\title{
An evaluation of nutritional practice in a paediatric burns unit
}

\author{
Sanne Vijfhuize, Manon Verburg, Luise Marino, Monique van Dijk, Heinz Rode
}

Introduction. Burn injuries evoke a systemic metabolic response with profound effects on organ function, susceptibility to infection, wound healing, growth and development, and mortality. Children are especially vulnerable to nutritional deficiencies owing to their limited energy reserves.

Methods. We evaluated the feeding practice in a paediatric burns unit. All children admitted to the unit were studied for a minimum of 3 consecutive days. Patients were divided into two groups: those with $<20 \%$ (group 1) and burns $\geq 20 \%$ of total body surface area (TBSA) (group 2). Dietary prescriptions, intake, compliance with feeding practices, and the use of supplementary nutrition were assessed. Underfeeding and over-feeding were defined when there was a discrepancy between prescribed and actual food intake.
Results. Forty children (mean age 5.8 years) were studied. They sustained between $2 \%$ and $55 \%$ TBSA burns. Inadequate caloric intake was seen in 19 of 29 patients and in 9 of 11 patients in groups 1 and 2, respectively. In contrast, excess protein supplementation was seen in 24 of 29 group 1 patients and 6 of 11 group 2 patients. The dietician's food prescription was followed for 170 of 211 days; prescription compliance was correct in only 39 of 211 days.

Conclusion. Adequate nutrition is essential for burns patients, but several factors can lead to either under- or over-feeding. A daily dietary consumption chart and evaluation of compliance are essential for each patient. There should be greater acceptability of tube enteral feeding.

S Afr Med J 2010; 100: 383-386
There have been rapid advances in burn care since 1939. Before World War II, the average burn size associated with a 50\% mortality rate was less than $30 \%$ of total body surface area (TBSA) burnt; currently, the LD50 has increased to $65-80 \%$ TBSA. ${ }^{1}$ This progress came about from effective resuscitation, infection control, early surgery, management of inhalation injuries and nutritional support.

A burn injury exceeding 15 - 20\% TBSA evokes a major and integrated systemic metabolic stress response, with changes in the metabolism of carbohydrates, proteins and lipids, thermal homoeostasis, and haematological, biochemical and endocrine systems, leading to severe catabolism, tissue breakdown, diminished immunity, retarded wound healing and multiorgan dysfunction. ${ }^{2}$ These conditions can persist until wound coverage and healing have completed - sometimes for up to 2 years. $^{2}$

The well-established beneficial effects of early enteral nutrition in thermal injuries have become an essential component of care. ${ }^{2,3}$ Children are especially vulnerable because a negative energy balance can easily develop - they

Erasmus MC-Sophia Children's Hospital, Rotterdam, The Netherlands Sanne Vijfhuize, MD

Manon Verburg, MD

Monique van Dijk, $\mathrm{PhD}$

Division of Dietetics, Red Cross War Memorial Children's Hospital, Cape Town Luise Marino, MMedSci Nut (Sheffield)

Division of Paediatric Surgery, Red Cross War Memorial Children's Hospital, Cape Town

Heinz Rode, MD, FRCS (Edin), MMed (Surg), FCS (SA)

Corresponding author: M van Dijk (m.vandijk.3@erasmusmc.nl) have smaller energy reserves, require extra calories for growth and development and, when sick, often cannot meet the required intake orally. ${ }^{4}$

Other factors contributing to nutritional depletion include chronic malnourishment, perioperative fasting periods, gastro-intestinal intolerance, septic episodes and physical activities. On the other hand, excessive nutritional support may compromise cardiac, pulmonary and renal functioning. Therefore, adequate nutrition demands high priority in the management of burn injuries, but is unfortunately often neglected in clinical practice. ${ }^{2}$

The purpose of our study was to evaluate nutritional intake in burnt paediatric patients, with the emphasis on required versus received nutritional intake, ward diet, and adherence to dietician instructions.

\section{Methods}

\section{Patients and setting}

All children admitted for at least 3 consecutive days to the Burns Unit at Red Cross War Memorial Children's Hospital were included. Discharge policies based on extent and depth of the wound and progress towards healing determined the period when the studies were conducted. Patients were divided into two study groups: those with burns less than $20 \%$ TBSA (group 1) and those with burns $\geq 20 \%$ TBSA (group 2). Although the length of the assessment periods varied between the two groups, the calculated nutritional needs and their provision remained the same for each patient. Children with $<20 \%$ TBSA burns were followed up for 3 consecutive days, and the others for 3 - 35 days. As this study only assessed dietary prescriptions, intake, compliance with feeding practices and supplementary nutrition, other nutritional parameters were not included in the final analysis. Under- and over- 
feeding were identified when there was a discrepancy between prescribed and actual intake.

\section{Dietary prescription}

A dietician specialising in the nutritional aspects of burn care, prepared individual dietary prescriptions including kilocalories, amount of protein and, where necessary, tube enteral or supplementary feeding.

Guidelines for this prescription were:

- protein: $<20 \%$ TBSA burned $-1.5 \mathrm{~g} / \mathrm{kg} /$ day; $\geq 20 \%$ TBSA burned $-3 \mathrm{~g} / \mathrm{kg} /$ day

- kilocalories (rule of Mayes): ${ }^{6} 0$ - 3 years $-108+68$ (pre-burn weight in $\mathrm{kg})+3.9 \times \%$ burn $=\mathrm{kcal} /$ day; $>3$ years $-818+$ 37.4 (pre-burn weight in $\mathrm{kg}$ ) $+9.3 \times \%$ burn $=\mathrm{kcal} /$ day.

\section{Dietary intake}

Actual dietary intake was retrieved from case record forms completed by nurses of the burns unit. Children were encouraged to eat all the offered food. To assess the quantity offered, the different components (starch, vegetables, meat/ fish) were weighed separately. The regular diet consists of three meals a day, with lunch and supper both warm meals. Porridge is the main component of breakfast. Food and snacks eaten between meals were also recorded. The feeding assistant kept a list of children who had not consumed their entire meal, and divided the leftovers into three categories: $1 / 4,1 / 2$ or $3 / 4$ of the total amount given. It was not possible to separate individual food components after a meal as mothers usually mix the foods for infants and, in older children, leftovers are scraped together. Although this process was the same for all children, it could lead to errors in caloric and protein intake calculations. By deducting the leftovers from the amount of food that was served, we calculated the actual dietary intake.

The energy and protein content of all food and drinks was calculated using the South African Food Composition Tables and Quantities Tables. ${ }^{5}$ Product information provided data on the composition of special supplements given to the patients.

Intake analysis

The number of kilocalories eaten per day was calculated for each patient and compared with the dietician's prescription, resulting in either an excess or deficit balance. In addition, the average balance per patient was computed by adding all daily balances and dividing the sum by the number of assessment days, which made computations of the average excess or deficit of kilocalories (per day) during the study period possible. Dividing the average excess or deficit by the prescribed amount $\times 100$ gave the average percentage overor underfeeding per child. The protein intake was calculated likewise, resulting in an average protein balance per child.

\section{Prescription compliance}

The intake section in the patient's folder was compared with the original dietary prescription for the type of food and volume provided. From the results of intake analyses, daily assessments were made for dietary prescriptions.

\section{Energy-enriched supplement}

An energy-dense complete feed for enteral use (Frebini Energy Fibre, Fresenius Kabi, $1.5 \mathrm{kcal} / \mathrm{ml}$ and $3.75 \mathrm{~g} / 100 \mathrm{ml}$ protein) is a frequently used carbohydrate-rich supplement. For patients with burns $\geq 20 \%$ TBSA, Frebini is prescribed to compensate for shortages in caloric intake. The daily dosage of Frebini given was recorded and converted to the amount of kilocalories ingested from Frebini on that day.

\section{Results}

Forty patients with a mean age of 5.8 yrs (range: 7 months - 11 years) were included; 29 had burns $<20 \%$ TBSA (range 2 - 19\%) (group 1), and 11 had burns $\geq 20 \%$ TBSA (range 20 - 50\%)(group 2). Hot water and flames caused 35 of the injuries. Children in group 1 were significantly younger ( 2.8 years) $(p=0.001)$. The type of burn also differed significantly, with $72 \%$ hot water burns in group 1 opposed to $9 \%$ in group $2(p=0.001)$.

\section{Dietary intake}

\section{Kilocalories}

Nineteen of the 29 patients in group 1 were underfed (range $0.5-63.5 \%$ ), and 10 were overfed (range $5.5-280.5 \%$ above the energy requirements prescribed by the ward dietician) (Table I). Table II sets out the data for group 2: 9 of the 11 patients were underfed (range $0.5-43 \%$ ); these figures were based on 3 - 35 days of assessments. The other 2 patients ate $3-19.5 \%$ in excess of the prescribed food.

Protein

Of the 29 patients in group 1, 24 had excess protein intake (range $1-226 \%$ ), and 5 received less than the calculated protein requirements (Table I). Three patients were followed up for more than 3 days, owing to complications resulting in prolonged hospitalisation. Six of the 11 patients in group 2 received $6-50 \%$ in excess of calculated requirements. The other 5 were protein-underfed, with a range of $24.5-43.5 \%$ below the prescribed protein requirements (Table II).

\section{Prescription compliance}

Dietary intake was compared with the original dietary prescription for 211 assessment days. The dietician's foodtype prescription was followed on 170 of 211 days (80.6\%), and the rate was correct for 55/211 days (26.1\%). Prescription compliance was correct in only 53 of the 211 days and, in 39 children, neither the type of food nor the amount provided was correct.

The average percentage of kilocalories from Frebini consumption was $64 \%$ (range $52-71 \%$ ) for 14 patients in group 1 , and $53 \%(47-58 \%)$ for the 11 patients in group 2.

\section{Discussion}

The study evaluated only the nutritional requirements, prescription practices and dietary outcomes of what the patients received, as an indication of the unit's nutritional practice. The latter was based on a specific feeding formula for paediatric burn patients, and was administrated either orally or enterally, by nasogastric or nasoduodenal tube. Oral and tube feeding was well tolerated; feeding was not interrupted by vomiting or diarrhoea.

Although the exact nutrient requirements of burns patients are debatable, it is accepted that maintenance of energy and protein requirements, replacement of high protein losses, 


\section{Original Articles}

Table I. Under- or excess feeding of patients with burns $<20 \%$ TBSA (group 1)

\begin{tabular}{|c|c|c|c|c|c|c|c|c|}
\hline No. & $\begin{array}{l}\text { Sex } \\
(M / F)\end{array}$ & $\begin{array}{l}\text { Age } \\
\text { (years) }\end{array}$ & $\begin{array}{l}\text { TBSA } \\
(\%)\end{array}$ & $\begin{array}{l}\text { Number } \\
\text { of days } \\
\text { assessed }\end{array}$ & $\begin{array}{l}\text { Average \% } \\
\text { (kcal) } \\
\text { under/over- } \\
\text { feeding }\end{array}$ & $\begin{array}{r}\text { Min. \% } \\
\text { (protein) }\end{array}$ & $\begin{array}{r}\text { Max. \% } \\
\text { (protein) }\end{array}$ & $\begin{array}{l}\text { Average \% } \\
\text { (protein) } \\
\text { under/over- } \\
\text { feeding }\end{array}$ \\
\hline 11 & $\mathrm{~F}$ & 1.5 & 2 & 3 & +152 & +44.6 & +61.7 & +51 \\
\hline 25 & $\mathrm{M}$ & 1.3 & 3 & 3 & -22 & -15 & +80 & +44 \\
\hline 10 & $\mathrm{~F}$ & 6.1 & 5 & 3 & -45.5 & +21.1 & +69.3 & +41.5 \\
\hline 23 & $\mathrm{M}$ & 2.8 & 5 & 3 & -5 & +31.7 & +112.6 & +65 \\
\hline 27 & $\mathrm{M}$ & 9.4 & 5 & 3 & -54.5 & -100 & +65.6 & -22.5 \\
\hline 8 & $\mathrm{M}$ & 1.4 & 6 & 3 & +75.5 & +215.3 & +247.4 & +226 \\
\hline 16 & $\mathrm{M}$ & 3.2 & 6 & 3 & +26.5 & +6.1 & +79.6 & +50.5 \\
\hline 20 & $\mathrm{~F}$ & 1.3 & 6 & 3 & +5.5 & +64 & +116.4 & +82 \\
\hline 21 & M & 2.0 & 6 & 11 & -33 & -25.3 & +179.4 & +69.5 \\
\hline 40 & M & 2.8 & 6 & 3 & -14.5 & -100 & -31.8 & -67 \\
\hline 19 & $\mathrm{~F}$ & 1.5 & 7 & 3 & +34 & +20.9 & +147.7 & +90 \\
\hline 28 & $\mathrm{~F}$ & 5.5 & 7 & 3 & -48.5 & -84.6 & +35.9 & -31.5 \\
\hline 24 & $\mathrm{~F}$ & 7.1 & 8 & 3 & -26.5 & -39.7 & +77.5 & +70.5 \\
\hline 14 & & 1.5 & 10 & 3 & +19.5 & -10 & +113.6 & +50.5 \\
\hline 34 & F & 2.9 & 10 & 3 & -63.5 & -100 & +38.5 & +1 \\
\hline 13 & & & 12 & 3 & -44.5 & -100 & +115 & -27 \\
\hline 18 & $\mathrm{M}$ & 4.3 & 12 & 3 & -0.5 & -25 & +128 & +76 \\
\hline 29 & M & 0.6 & 12 & 3 & -28 & -78 & +104 & +16 \\
\hline 30 & M & 2.9 & 14 & 7 & -11.5 & -100 & +252.7 & +56 \\
\hline 36 & M & 2.0 & 14 & 3 & -13.5 & -23.2 & +49.6 & +20.5 \\
\hline 4 & $\mathrm{~F}$ & 0.9 & 15 & 3 & +26 & +25 & +76.3 & +56.5 \\
\hline 15 & $\mathrm{~F}$ & 5.0 & 15 & 3 & -45 & +7.3 & +54.3 & +25.5 \\
\hline 22 & M & 0.7 & 15 & 3 & -2 & -22.8 & +53.6 & +25 \\
\hline 35 & M & 3.9 & 15 & 3 & +11.5 & +17.2 & +112.8 & +59 \\
\hline 39 & M & 5.2 & 15 & 14 & +30 & -37.5 & +246.3 & +172.5 \\
\hline 9 & $\mathrm{~F}$ & 1.8 & 16 & 3 & +280.5 & +21.6 & +87.2 & +54.5 \\
\hline 7 & $\mathrm{~F}$ & 1.0 & 18 & 3 & -8 & +65.4 & +127.9 & +104.5 \\
\hline 31 & M & 5.5 & 18 & 3 & -11 & -4 & +107.1 & +42.5 \\
\hline 12 & M & 0.8 & 19 & 3 & -12 & -60.7 & -1.8 & -4 \\
\hline
\end{tabular}

\section{Table II. Under- or over-feeding of patients with burns $>20 \%$ TBSA (group 2)}

\begin{tabular}{|c|c|c|c|c|}
\hline $\begin{array}{l}\text { Age } \\
\text { (years) }\end{array}$ & TBSA (\%) & $\begin{array}{l}\text { Number } \\
\text { of days } \\
\text { assessed }\end{array}$ & $\begin{array}{l}\text { Average \% } \\
\text { (kcal) under-/ } \\
\text { over-feeding }\end{array}$ & $\begin{array}{l}\text { Average \% } \\
\text { (protein) under-/ } \\
\text { overfeeding }\end{array}$ \\
\hline \multirow[t]{2}{*}{10.1} & 20 & 35 & -43 & -38 \\
\hline & 20 & 3 & -29.5 & +50 \\
\hline 5.7 & 20 & 15 & -35 & -31 \\
\hline 0.9 & 22 & 9 & +3 & +37.5 \\
\hline 6.9 & 25 & 3 & +19.5 & +19.5 \\
\hline 10.5 & 25 & 10 & -32 & -24.5 \\
\hline 11.3 & 29 & 9 & -42.5 & -42.5 \\
\hline 4.8 & 30 & 20 & -1.5 & +6 \\
\hline 4.5 & 40 & 29 & -0.5 & +15.5 \\
\hline 10.3 & 50 & 31 & -37.5 & -43.5 \\
\hline 7.6 & 55 & 26 & -6.5 & +40.5 \\
\hline
\end{tabular}

trace elements and other micronutrients is vital. Weight as a measure of nutritional status should not decrease by more than $10 \%$ of the admission weight throughout the hospitalisation period. Protein losses also take much longer to replenish, even with adequate nutrition and exercise, and should therefore be carefully managed. On the other hand, acute nutritional losses incurred for any reason are very difficult to replenish over a short period. Acute over-feeding can lead to hyperglycaemia, fatty liver and renal abnormalities. A stressbased hypermetabolism cannot be reversed by over-feeding until the hormonal imbalances caused by the burn lesions have returned to normal. ${ }^{1}$
Children have smaller reserves and greater caloric and protein requirements than adults and, if starved, rapidly enter into a negative balance. Consequently, the tendency is to initiate feeding as soon as possible, especially early enteral feeding for moderate to major burns. ${ }^{7,8}$ Parenteral nutrition confers no advantages over enteral nutrition, if the latter is feasible, and all burn patients in our study could easily be managed with enteral feeding.

A minority of patients received excess feeding during the study period, which might have been caused by the overuse of Frebini tube feeding despite adequate oral intake, or incorrect tube feeding rates. This expensive energy- and protein-rich 


\section{Original Articles}

drink is frequently used, especially at night. For patients with extensive burns, Frebini is ideal for compensating for shortages in caloric intake, which justifies the cost. Although patients with lesser burns did not need this supplement, it was given to almost every second patient and, at times, when not prescribed or requested by the children.

Of concern was the low compliance with dietetic prescriptions, which were followed in only $25 \%$ of the assessment days. This fact contributed to both the under- and over-feeding rates, and made it difficult for the ward dietician to work effectively. We identified several single and multiple factors that, although not specifically documented for each patient, led to underfeeding in $82 \%$ of patients with major burns and $66 \%$ of those with lesser burns. Underfeeding resulted from anorexia due to the burn injury, long starvation periods before and after surgery, questionable quality of the ward diet, and eating difficulties owing to splints, unhealed wounds, the ward environment, and the absence of parents. A multimodal approach is required to overcome these practical shortcomings, and should include improving the ward diet and catering for special needs, appointing a nutritional nurse and/or volunteers to help young or incapacitated patients, and encouraging caregivers to stay with their children.

In conclusion: We demonstrated that meeting nutritional requirements is difficult in a paediatric burns population, and we identified several contributing factors.

To balance prescribed and actual intake, the following should become standard practice:

- The nutritional needs, as determined by the thermal injury, pre-morbid status and individual factors, must be determined for each patient at outset.
- Dietetic instructions must be clear and be followed, and any deviation must be substantiated. A daily dietary consumption chart is essential, and nutritional follow-up is advised for each patient, especially in complicated cases.

- Supplementary feeds must be used judiciously.

- Enteral tube feeding should be encouraged, especially in children with major burns, those who require frequent surgical procedures, and where other factors may influence adequate oral intake.

- Nutritional education must become part of daily unit routine; the introduction of a nutritional nurse and feeding volunteers to help incapacitated children to eat is recommended.

\footnotetext{
References

1. Deitch EA. Nutritional support of the burn patient. Crit Care Clin 1995; 11: 735-750

2. Jeschke MG, Chinkes DL, Finnerty CC, et al. Pathophysiologic response to severe burn injury. Ann Surg 2008; 248(3): 387-400

3. Hart DW, Wolf SE, Chinkes DL, et al. Effects of early excision and aggressive enteral feeding on hypermetabolism, catabolism, and sepsis after severe burn. J Trauma 2003; 45: 755-764.

4. Trocki O, Michelini JA, Robbins ST, Eichelberger MR. Evaluation of early enteral feeding in children less than 3 years old with smaller burns (8-25 per cent TBSA). Burns 1995; 21: 17-23.

5. South African Medical Research Council. Food Composition Tables. 3rd ed. Cape Town: Medical Research Council, 1991.

6. Mayes T, Gottschlich MM, Khoury J, Warden GD. Evaluation of predicted and measured energy requirements in burned children. J Am Diet Assoc 1996; 96: 24-29

7. Chiarelli A, Enzi G, Casadei A, et al. Very early nutrition supplementation in burned patients. Am J Clin Nutr 1990; 51: 1035-1039.

8. Venter M, Rode H, Sive H, Visser M. Enteral resuscitation and early enteral feeding in children with major burns - effect on McFarlane response to stress. Burns 2007; 334: 464-471.
}

Accepted 31 August 2009. 